\title{
Visita à Imunologia
}

\author{
Visiting Immunology
}

Nelson Monteiro Vaz' ${ }^{1}$, Vitor Pordeus ${ }^{2}$

${ }^{1}$ Departamento de Bioquímica e Imunologia, ICB, UFMG e ${ }^{2}$ Centro de Ensino e Pesquisa do Hospital Pró-Cardíaco - PROCEP - Belo Horizonte, MG - Rio de Janeiro, RJ

\section{IMUNIDADE ESPECÍFICA: UMA ÚNICA MANEIRA DE VER?}

\section{As perguntas especificam as respostas}

"Sem mais evasivas, Professor: o senhor é ou não é comunista?" - indagava o coronel a Haity Moussatché no IPM (Inquérito Policial Militar) de Manguinhos, em 1968. "Coronel, há perguntas às quais não se pode responder sim ou não. Por exemplo: O senhor ainda bate em sua mulher?" - foi a brilhante resposta. Esta lembrança do grande mestre ilustra que as perguntas estabelecem o que podem ser as respostas.

Porque se perguntamos: "Qual o estado atual da imunologia?", ou "Para onde a imunologia nos conduz?" ou "O que falta à imunologia contemporânea?", já o fazemos com expectativas definidas. Essas perguntas pressupõem um entendimento prévio do objeto de estudo da imunologia: elas se apóiam no entendimento de que a imunologia estuda o "estranhamento" de materiais que não pertencem ao corpo (antígenos), principalmente, agentes infecciosos, como bactérias, vírus e parasitas, que acionam mecanismos moleculares/celulares; que esses processos, usualmente, facilitam a eliminação desses materiais do corpo $^{1,2}$; que, desregulados, esses mecanismos podem levar a reações excessivas ("alérgicas") a agentes que seriam inócuos ${ }^{3,4}$, ou, a autoagressões a tecidos e órgãos do corpo ${ }^{5}$. Uma revisão compacta com base nessas premissas alinharia uma série de progressos na descrição de múltiplos componentes genéticos/ moleculares/ celulares envolvidos nesse "estranhamento" e em sua "regulação", usualmente conhecida como "tolerância imunológica"6. Em resumo: se considerarmos que já sabemos do que trata a imunologia, nossa expectativa sobre uma descrição do "estado da arte" está bastante definida.

\section{Um viés cognitivo}

Algo diverso ocorre se não houvermos ainda decidido quais são as perguntas adequadas. Usualmente, o "estranhamento" em que a imunologia se baseia é aceito tacitamente, como se soubéssemos o que isso significa. Mas sabemos? Esse "estranhamento" é uma atividade decisória pela qual supomos que o corpo separa o que lhe pertence do que não lhe pertence - uma atividade cognitiva. Nessa opção, nossas investigações estarão baseadas naquilo que entendemos como cognição. Termos-chave da imunologia, como reconhecimento específico, memória, tolerância, regulação, supressão, etc, estão todos baseados nesse entendimento. Dizer que a atividade imunológica é "defensiva" não nos ajuda a entender essa defesa que, além disso, não é um "mecanismo", mas sim um resultado, uma conseqüência possível da integração de vários mecanismos celulares e moleculares.

\section{Imunidade adaptativa e inata}

A imensa maioria dos animais, os invertebrados, não tem linfócitos, não possui os mecanismos somáticos de geração da diversidade de receptores de membrana criados e expressos na linfopoiese, nem o complexo gênico (MHC) que gera as moléculas onde se encaixam os peptídeos (produtos do $\mathrm{MHC}$ ) aos quais se ligam os receptores dos linfócitos T (TCR) que são ativados. As relações dos invertebrados com germes, vírus e parasitas envolvem uma multiplicidade de outros mecanismos, muitos dos quais estão também presentes nos vertebrados. Influenciando a imunidade dependente de linfócitos, exibida nos vertebrados (imunidade adaptativa), e sendo por ela influenciados, os imunologistas descreveram esses processos comuns a vertebrados e invertebrados como parte de uma imunidade inata, herdada, estereotipada, menos flexível que a imunidade dependente de linfócitos ${ }^{7}$.

Também aqui, encarar toda essa variedade de processos como "defensiva", oculta o fato de que essa defesa não é um "mecanismo", mas sim um resultado possível da integração de vários mecanismos. Tanto em vertebrados como em invertebrados, como em plantas, os mecanismos da imunidade, ou seja, aqueles que participam de processos que resultam na "defesa" do organismo em suas relações com germes, vírus e parasitas, são mecanismos do viver, estão envolvidos em

Correspondência: Nelson Vaz - Rua Campo Basso, 150-31340-330- Bandeirante - Belo Horizonte, MG 
montar e manter o organismo, são parte de sua fisiologia. Não há mecanismos especiais "de defesa" que possam ser destacados da montagem e manutenção do organismo como um todo. Seja "inata" ou "adaptativa", o que chamamos imunidade é uma conseqüência do viver e sua compreensão depende do entendimento desse viver ${ }^{8}$.

\section{Conflitos atuais}

A imunologia vive uma séria crise conceitual. Sua principal teoria, a Teoria da Seleção Clonal, criada nos anos 1950-60, sobreviveu a sucessivos ataques por meio de notáveis malabarismos. Recentemente, porém, ela foi gravemente atingida por três linhas de evidência que ela não consegue acomodar em seus postulados. Primeiro, a especificidade dos linfócitos T, a célula-mestre, na ativação e regulação da atividade imunológica, é profundamente degenerada ${ }^{9}$. Um único peptídeo acoplado ao MHC pode interagir milhares de TCR distintos, e cada TCR é capaz de ligar uma grande multiplicidade de peptídeos ${ }^{10}$. Segundo, há uma abundância de linfócitos auto-reativos ativados em organismos que permanecem sadios ${ }^{11}$. Terceiro, organismos adultos se tornam facilmente "tolerantes" a proteínas imunogênicas que contatam por vias mucosas ${ }^{12}$, fenômeno conhecido como tolerância oral.

Assim sendo, no nível celular / molecular, nada é tão específico como parecia; a "tolerância" a componentes do corpo ("tolerância natural") envolve uma intensa reatividade de linfócitos com esses componentes ${ }^{11}$; e a "tolerância" a proteínas externas ${ }^{12}$ requer organismos imunocompetentes ${ }^{13}$, e não neonatos imaturos, como previa a teoria.

Tornou-se difícil imaginar como o sistema imune protege o corpo, ou como o corpo adoece imunologicamente. O mecanismo proposto para as "doenças autoimunes" se baseava no surgimento de clones autoreativos. Mas esses clones estão presentes e ativados em organismos sadios; apenas não exibem a reatividade progressiva que é característica das respostas imunes secundárias, a chamada "memória" imunológica14. Estamos todos expostos a materiais alergênicos, mas apenas alguns de nós tornam-se alérgicos. Cada vez mais, entendemos que estamos embebidos em um meio repleto de germes, e que apenas excepcionalmente estes se tornam patogênicos. Apenas a mucosa oral abriga seiscentas espécies de bactérias ${ }^{15}$.

\section{Maneiras de ver}

Podemos optar por ver da maneira usual e pensar, por exemplo, que o problema das doenças auto-imunes agora se resume em encontrar os mecanismos que ativam células dendríticas e conferem aos clones auto-reativos uma reatividade progressiva que os torna patogênicos ${ }^{16}$. Ou podemos abandonar a perspectiva "cognitiva" usual e buscar outra maneira de ver. Mas, para isso, temos que criar outras perguntas e abandonar as expectativas anteriores. E isso não é fácil. Vejamos.
A maneira de ver prevalente na imunologia tem duas características fundamentais. Conceitualmente, a atividade imunológica tem um aspecto cognitivo velado que, embora não esteja no centro das atenções, governa todo o entendimento, gera todas as perguntas e determina os critérios de validação das respostas obtidas. A mudança dessa situação requer um entendimento claro do que aceitamos como cognição e se essa é uma opção adequada para descrever os fenômenos imunológicos.

Experimentalmente, a imunologia é dominada por um modelo estímulo-resposta (estimulo imunogênico à resposta imune específica), hoje camuflado pelo interesse na "regulação" dessas respostas - que, entretanto, só consegue ser vista como uma "resposta regulatória". A mudança dessa situação requer a substituição do modelo estímulo-resposta e a opção por outra maneira de ver a atividade imunológica.

No centro do modelo estímulo-resposta está uma "caixa preta" (black box), assim definida: "Uma caixa preta é desenhada quando parte de uma máquina ou um conjunto de comandos é demasiado complexo para ser mostrado em uma prancha de desenho. Tudo o que precisa ser dito sobre essa caixa é que um certo estímulo (input) permite a previsão de uma certa resposta (output). Com base nessa correspondência entre estímulo e resposta, o sistema complexo entre eles (entre o estímulo e a resposta) pode ser visto como algum tipo de unidade. Independentemente de seus componentes e independentemente da complexidade de suas relações entre si, o sistema - a caixa preta - opera como uma unidade".

O esforço dos imunologistas pretende iluminar o interior da caixa-preta, mas o que é necessário é eliminar a caixapreta, desenvolver uma outra maneira de ver.

\section{O CARÁter COGNITIVO dA IMUNOLOGIA, A BIOLOGIA DO CONHECER E UMA PROPOSTA DE SUBSTITUIÇÃO}

No modo de ver usual, a atividade imunológica surge quando linfócitos "estranham" (reconhecem) a invasão do corpo por materiais (imunogênicos) que não the pertencem. Em conseqüência desse caráter "cognitivo" (reconhecedor) atribuído ao sistema imune, são freqüentes as analogias traçadas entre o sistema imune e o sistema nervoso, o sistema cognitivo por excelência ${ }^{17}$. Essa analogia, no entanto, pode conduzir a equívocos, se não atentarmos para o que entendemos por cognição.

De acordo com o neurobiólogo / filósofo chileno Humberto Maturana, podemos descrever os seres vivos em dois domínios distintos: no domínio de sua dinâmica de constituição, e no domínio de suas relações com o meio. Quando observamos uma determinada ação e dizemos que ela é cognitiva, (por exemplo, um animal que nos parece reconhecer algo) estamos qualificando 
tais ações do organismo. Estas ações surgem em um meio, no qual o organismo opera como uma totalidade ${ }^{18,19}$. É nesse meio, nesse segundo domínio, que vemos o organismo se relacionar com entidades de diferentes tipos. Como parte do organismo, o sistema nervoso opera em um domínio diferente daquele em que vemos o organismo agir. Em sua dinâmica interna, o sistema nervoso opera como uma rede fechada de relações cambiantes de atividade entre seus elementos componentes, principalmente neurônios. Não interage diretamente com os tipos de entidades com as quais 0 organismo interage. 0 sistema nervoso atua sobre 0 organismo e, de forma recíproca, o organismo atua sobre o sistema nervoso, em uma dança de atividades que perdura enquanto perdura o organismo.

Usualmente, o sistema nervoso e, também, o sistema imune, são vistos como sistemas abertos às interações com elementos do meio onde o organismo opera. O sistema nervoso está ligado a receptores sensíveis a estímulos (óticos, acústicos, olfativos, etc) partidos do meio. Mas, na maneira de ver proposta por Maturana, esses receptores pertencem ao organismo e não, propriamente, ao sistema nervoso; fazem parte das superfícies sensoriais através das quais o sistema nervoso interage com o organismo ${ }^{18,19}$. Nos foto-receptores da retina há, inclusive, uma sugestão morfológica, um estreitamento, que parece dividir a célula em duas partes: uma tipicamente neuronal, que pertence ao sistema nervoso e outra, tipicamente sensorial, que pertence ao organismo.

Nessa maneira de ver, o sistema nervoso não é um sistema cognitivo. A cognição não reside no sistema nervoso, e a mente, aquilo que identificamos como "mental", não está na cabeça: surge na conduta, nas ações do organismo em relação com elementos do meio ${ }^{20}$. E ao aplicar essa maneira de ver ao sistema imune, surge uma visão muito diferente da atividade imunológica.

Os receptores expressos nos linfócitos (BCR e TCR, respectivamente em linfócitos $B$ e T) constituem uma grande coleção de moléculas geradas somaticamente de novo na ontogênese de cada organismo ${ }^{1}$. 0 processo de geração dessa diversidade linfocitária admite uma fase aleatória ou, pelo menos, não conhecemos a ordem complexa que a determina. Assim, usualmente, se admite que a atividade imunológica flutua ao sabor das circunstâncias. No entanto, os linfócitos gerados em cada organismo têm um alto grau de conectividade interna e se organizam em uma rede de conexões extremamente robusta, resistente a mudanças, que se forma cedo na vida do animal ${ }^{21}$, sob a influência de imunoglobulinas maternas $^{22}$, e permanece estável durante todo o seu viver saudável, a despeito de sua contínua interação com elementos moleculares do meio (antígenos) ${ }^{23}$ e do surgimento daquilo que os imunologistas registram como "respostas imunes", capazes de modificar rapidamente a composição linfocitária do organismo ${ }^{24}$.

Assim, embora sem dispor de uma topologia, de um mapa mais ou menos permanente, de conexões intercelulares, como a exibida por neurônios no sistema nervoso, os linfócitos também se organizam em uma malha, ou rede de organização invariante ${ }^{25}$. Esse caráter robusto da rede de interações linfocitárias pode ser acessado por medidas da reatividade "global" das imunoglobulinas circulantes, principalmente das IgM, conseguidas através de técnicas modificadas de immunoblot ${ }^{26}$.

Nossa posição privilegiada de observadores permitenos ver, ao mesmo tempo, a dinâmica estrutural do organismo e as interações do organismo como um todo em seu meio. Assim, podemos ver que certas modificações estruturais se dão simultaneamente ou logo após certas interações com o meio e concluir, equivocadamente, que a mudança estrutural do organismo foi causada (determinada, especificada, guiada) pela interação com o meio. Isso é o que Maturana chama de "falácia das interações instrutivas"18,19.

No caso do sistema nervoso, podemos nos equivocar ao registrar uma correlação entre a atividade neuronal e a conduta do organismo em seu meio, como se a atividade do sistema nervoso fosse determinada (especificada, guiada) pelas interações com o meio. Na realidade, a atividade do sistema nervoso é estruturalmente determinada (especificada, guiada) e depende da dinâmica estrutural em curso no sistema nervoso, a cada instante. As interações com o meio podem apenas desencadear mudanças determinadas (especificadas, guiadas) pela estrutura do sistema nervoso naquele instante ${ }^{18,19,27,28,29}$.

Similarmente, no caso do sistema imune, podemos nos equivocar ao registrar uma correlação entre a atividade linfocitária (a expansão de certos clones e a inibição de outros) e o contato do organismo com materiais (antígenos) absorvidos de seu meio, como se a atividade do sistema imune fosse determinada (especificada, guiada) pelas interações com materiais antigênicos. No entanto, as interações com materiais antigênicos podem apenas desencadear mudanças determinadas (especificadas, guiadas) pela estrutura do sistema imune naquele instante ${ }^{14,28,29}$.

Isso não significa que não se possa, como é usual, registrar e quantificar, através de imunoensaios, a ativação linfocitária e sua participação naquilo que entendemos como "respostas imunes específicas" ou sua "regulação". Modificações na dinâmica linfocitária estão ocorrendo todo o tempo, inclusive em seqüência ao contato do organismo com materiais antigênicos; mas, na forma usual de ver a atividade imunológica, esta é exclusivamente "específica", ou seja, diz respeito apenas aos linfócitos capazes de interagir diretamente com materiais imunogênicos; o restante da atividade é considerada subsidiária, ou regulatória. Outros imunologistas argumentam que a especificidade imunológica é degenerada, frouxa, ampla 9; que os mesmos padrões de atividade imunológica surgem em animais privados de exposições antigênicas ${ }^{23}$ e se regeneram quando o sistema é desestruturado, por exemplo, por irradiação letal ${ }^{25}$; que há muitos linfócitos que reagem com outros linfócitos e com 
componentes do organismo ${ }^{11}$; enfim, que há uma constância na atividade imunológica que não existiria, se a atividade do sistema imune fosse movida por contatos antigênicos.

Tudo depende, afinal, da maneira de ver que adotarmos. Se virmos o sistema imune como um sistema cognitivo, funcional e defensivo, adaptado para a detecção e eliminação de materiais estranhos ao corpo, investigaremos os mecanismos genéticos/celulares/ moleculares responsáveis por essas funções. Nesse processo, atribuiremos ao sistema imune a possibilidade de interagir com elementos do meio em que o organismo vive (antígenos) e, nessas interações, estabelecer uma dinâmica regulada de "respostas imunes" que serve ao organismo em situações anormais, mas não tem conexões importantes com sua fisiologia.

Por outro lado, se descrevermos o sistema imune como uma parte da dinâmica de composição do organismo, que está em contínua interação recíproca com o restante do organismo, investigaremos os mecanismos genéticos / celulares / moleculares responsáveis pela integração do sistema imune na fisiologia do organismo.

Na primeira maneira de ver, os objetivos fundamentais são o entendimento do mecanismo de desencadeamento e regulação das "respostas imunes específicas" e sua "regulação", que inclui o que hoje se descreve como "tolerância natural", ou seja, a ausência de respostas imunes a componentes do próprio corpo em condições saudáveis. Alcançados esses objetivos, teríamos uma explicação das atividades "cognitivas" do sistema imune, a fonte do "reconhecimento" de materiais estranhos e da "memória" imunológica, assim como da ausência de auto-agressões.

Na segunda maneira de ver, os objetivos fundamentais da imunologia são: a) a descrição da organização do sistema imune, ou seja, do conjunto de relações entre componentes que o sistema mantém invariante; e, b) a descrição dos limites (interfaces e interseções) entre o sistema imune e o organismo.

Alcançados esses objetivos, teríamos a possibilidade de explicar a atividade imunológica e sua participação na fisiologia do organismo, ou seja, a dinâmica de interações recíprocas entre o sistema imune e o organismo do qual ele é parte.

\section{A CONSERVAÇÃo DA ATIVIDADE IMUNOLÓGICA}

A geração da diversidade linfocitária foi concebida como um processo aleatório, pois isso parecia necessário para gerar uma coleção tão vasta de receptores que fosse capaz de reagir com qualquer antígeno encontrado pelo organismo, nas eventualidades de seu viver. E, realmente, a genética molecular comprovou que há etapas aleatórias na montagem das regiões variáveis das imunoglobulinas e dos receptores de célula $\mathrm{T}^{30,31}$ e isso parecia comprovar a ausência de uma ordem mais abrangente na atividade linfocitária. No entanto, há restrições importantes na diversidade linfocitária.

\section{Restrições na diversidade}

A primeira restrição à idéia de uma versatilidade ilimitada surgiu nos anos 1960-70, ficando conhecida como o "controle genético da reatividade imune" e levou à caracterização dos genes Ir (Imune-resposta) ligada ao $\mathrm{MHC}^{32}$. A segunda restrição, nessa mesma época, mostrou que as interações dos linfócitos $\mathrm{T}$ eram "restritas" a células com o mesmo MHC ${ }^{33}$. Essa "restrição pelo MHC" constitui um mistério que perdurou por cerca de 15 anos e só foi solucionado com o entendimento do "processamento" e "apresentação" de peptídeos, em meados dos anos 1980 34,35.

Surgiu então o entendimento de que a reatividade imunológica individual está ancorada na constituição genética, através de três complexos gênicos: o MHC (Major Histocompatibility Complex), cujos produtos "apresentam" os peptídeos processados; e dois conjuntos gênicos, em cromossomos distintos, que codificam as cadeias dos receptores clonais de linfócitos B (BCR, as imunoglobulinas) e os TCR. Esses receptores, porém, são montados, de novo, em cada organismo, em um processo que admite etapas aleatórias e gera uma enorme variedade de configurações em cada organismo e continuamente as modifica durante o viver (fig. 1).

As etapas iniciais da organização do sistema imune se dão em presença de imunoglobulinas maternas, que influenciam significativamente como essa organização se dá22. Além disso, em seu viver, cada ser vivo atravessa diversas contingências e seria esperado que cada organismo, a cada etapa de sua vida, exibisse uma coleção diferente de linfócitos, pois linfócitos estão entre as células com um alto índice de reposição ${ }^{25}$. Seria também esperado que o espectro de reatividades específicas em cada organismo dependesse de suas experiências passadas.

Por tudo isso, seria extremamente improvável encontrar padrões, perfis repetidos de reatividade linfocitária em organismos distintos, mesmo que eles tivessem a mesma composição genética, como entre animais de uma mesma linhagem isogênica. Assim, o encontro de padrões estáveis na reatividade de imunoglobulinas normais ("anticorpos naturais") em diversas espécies animais, inclusive em humanos, longe de ser uma curiosidade desconexa, constitui uma forte razão para mudarmos toda a nossa maneira de ver a atividade imunológica.

\section{Padrões de reatividade nas imunoglobulinas normais}

Tradicionalmente, os testes imunológicos estão dirigidos para detectar e quantificar reações específicas, e muitos esforços foram feitos para trabalhar com reagentes altamente purificados. Além disso, a maioria dos experimentos investiga o que se passa com animais 


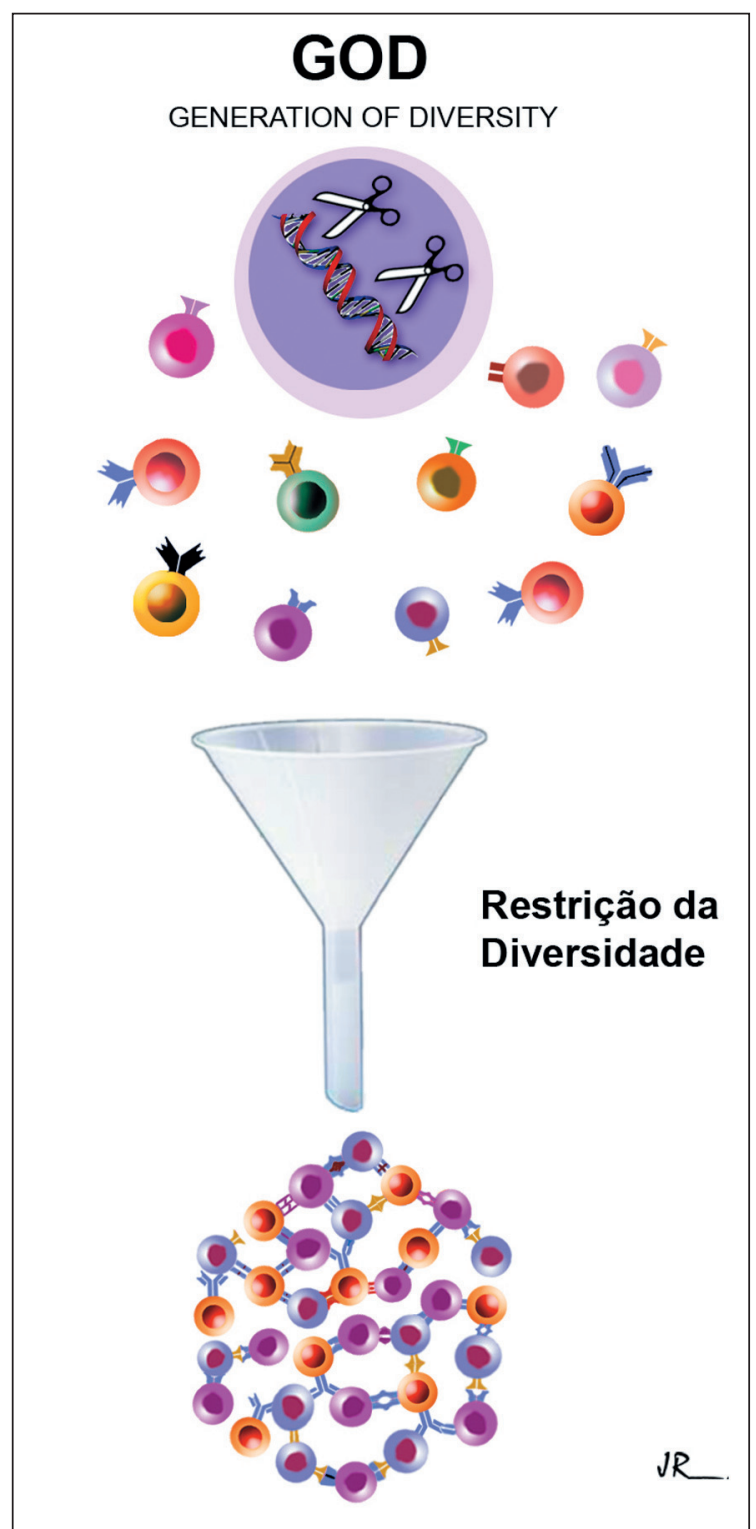

Fig. 1 - Montagem e manutenção do sistema imune. No alto da ilustração podemos ver um progenitor linfóide com representações das enzimas que promovem os rearranjos gênicos geradores dos receptores clonais. Estes exibem configurações únicas representadas como figuras geométricas nos receptores (Geração da Diversidade, Generation of Diversity - GOD - em ing/ês). Em seguida, os receptores são submetidos a uma seleção de repertório, culminando na montagem de relações celulares que se constituem invariantes ao longo da vida do indivíduo como ilustrado na região inferior. Perturbações imunológicas ocorrem quando esta rede de relações invariantes é deslocada

imunizados, em condições bem definidas. Por tudo isso, experimentos que medem a reação do soro total de animais normais, não imunizados, com misturas complexas de muitos antígenos, pareceriam fora de propósito.

Essa foi, no entanto, a idéia desenvolvida com sucesso pelo matemático / imunologista Alberto Nóbrega ${ }^{1}$ e cols., que desenvolveram uma forma modificada de immunoblot e um software sofisticado para analisar seus resultados 25,36,37. Nesse método, uma solução contendo muitas proteínas, como um extrato de músculo, ou fígado, ou de uma cultura bacteriana, é inicialmente separada por eletroforese (PAGE) e, então, exposta ao soro. Imunoglobulinas presentes no soro reagem, em diferentes graus, com diferentes antígenos, e a intensidade dessa reação é revelada por anticorpos secundários (anti-lgM, ou anti-lgG) marcados com enzimas. A revelação mostra uma floresta de picos de reatividade, que o sofisticado software desenvolvido por Nóbrega e colaboradores permite analisar e comparar quantitativamente a resultados obtidos com outros soros.

Com esse método, foi possível mostrar que imunoglobulinas naturais humanas exibem padrões de reatividade com misturas protéicas complexas que permanecem espantosamente estáveis durante, no mínimo, 25 anos, em humanos adultos ${ }^{26}$. Camundongos estabelecem cedo, na ontogênese, seus padrões de formação de IgM, e os mantêm estáveis, mesmo quando criados em condições "isentas de antígenos"23; linhagens isogênicas distintas têm perfis distintos de reatividade e essas diferenças dependem dos complexos gênicos importantes na determinação da reatividade imunológica ${ }^{37}$. Cavalos mantêm estáveis os perfis de reatividade das IgM e grande parte dos perfis das IgG, mesmo durante os regimes brutais de hiperimunização usados na produção de anti-soros terapêuticos, como o soro anti-tetânico ${ }^{38}$.

\section{O significado da atividade conservadora}

A existência desses padrões estáveis de reatividade contradiz a idéia de um sistema imune movido por uma atividade "reconhecedora" de materiais estranhos, montado ao acaso, e variando de acordo com as contingências dos encontros com materiais antigênicos. Essa idéia é menos surpreendente, quando imaginamos o sistema imune como uma rede complexa interconectada, na qual os linfócitos interagem entre si e com múltiplos componentes do organismo, e isso the confere uma robustez dinâmica, reveladora de que, apesar da intensa substituição de elementos, sua organização permanece invariante. É também útil considerar que o sistema imune está cotidianamente exposto a uma grande quantidade de proteínas estranhas, através da alimentação e do contato com a microbiota autóctone. A substituição das proteínas da dieta por uma fórmula rica em aminoácidos tem sérias conseqüências sobre a estrutura histológica do tecido linfóide associado ao intestino, do timo e de linfonodos periféricos, além de afetar drasticamente a produção de IgA secretória, de $\operatorname{lgG}$ e IgA do soro, mas não a produção de $\operatorname{lgM}{ }^{39}$. As proteínas dos alimentos estão direta ou indiretamente envolvidas na produção de grande parte das imunoglobulinas circulantes e das que são secretadas nas mucosas.

Estudos com animais germ-free (isentos de germes) mostram que também a microbiota autóctone contribui significativamente nessa reatividade imunológica nor$\mathrm{mal}^{40}$. O que é importante ressaltar é que, embora 
estejamos expostos diariamente a essas mesmas proteínas da dieta e da flora, o sistema imune normal não manifesta uma reatividade progressiva, exibe padrões claramente estáveis, não desencadeia "respostas imunes secundárias" e conserva estáveis os níveis de imunoglobulinas reativos com as proteínas da dieta e da flora ${ }^{41}$.

\section{Imunoglobulinas e anticorpos específicos}

Uma análise global das imunoglobulinas do plasma permite a visão de apenas um lado da imensa complexidade celular/molecular do sistema imune. Mas, mesmo dentro dessa limitação, essa análise permite conjecturas sobre toda uma outra maneira de ver a atividade imunológica.

É impossível contar a história de eventos ao acaso. Variações só fazem sentido contra um fundo de constância. A caracterização de padrões estáveis, na atividade imunológica, constitui um primeiro passo importante na definição de uma organização para o sistema imune. Esse primeiro passo mostra um sistema ancorado em genes importantes na atividade imunológica ( $\mathrm{MHC}$ e genes que codificam receptores clonais, BCR e TCR); indivíduos distintos que compartilham esses genes, compartilham também perfis de reatividade, principalmente das IgM, com misturas complexas de antígenos; com misturas diferentes de antígenos, mudam os perfis, mas indivíduos geneticamente idênticos compartilham os mesmos perfis ${ }^{37}$.

Desde tenra idade, os mesmos perfis de reatividade das IgM são mantidos durante o viver sadio, a despeito da contínua reposição de componentes que ocorre no sistema imune normal ${ }^{22}$. Quando o sistema imune é destruído por níveis letais de irradiação, e o animal é resgatado da morte por transfusões de fígado fetal ou medula óssea singênica, em alguns meses, os mesmos padrões de reatividade são restabelecidos ${ }^{25}$. Isso significa que os referenciais que orientam a organização do sistema imune são internos ao organismo.

Finalmente, como discutido a seguir, durante desvios patológicos graves, como doenças auto-imunes ou formas severas de parasitoses, tanto humanas quanto experimentais, ocorrem desvios nos padrões de reatividade das IgG que são característicos do estado patológico. Por exemplo, formas severas de malária humana ${ }^{42}$, de esquistossomose ou leishmaniose experimental murina ${ }^{43}$, mostram modificações características nos perfis de reatividade das imunoglobulinas. Isso sugere que em organismos distintos, formas patológicas específicas de doenças auto-imunes ou parasitoses envolvam os mesmos referenciais de mudança.

\section{O EMERGIR DA IMUNOPATOLOGIA}

A imunologia nasceu do estudo de doenças infecciosas, associada à Teoria dos Germes, de Pasteur, na proposta de que elas são causadas por germes específicos. Ao mesmo tempo, Pasteur propôs também a imunização preventiva, com formas "atenuadas" dos agentes infecciosos específicos ("vacinação"). O conjunto dessas duas propostas revolucionou a medicina experimental e gerou um enorme entusiasmo na busca de "agentes específicos" de doenças que, praticamente, fundou a investigação "biomédica" que, por sua vez, revolucionou a medicina ${ }^{44}$.

Caracterizar esses "agentes específicos", mostrar que eles eram capazes de promover um simulacro da doença em animais de laboratório tornou-se mais importante que entender a própria natureza da doença, ou seja, entender o que acontece no "adoecer". Hoje, conhecemos uma grande variedade de agentes (ou agências) patogênicos (as), mas entendemos muito menos sobre o que se passa no "adoecer", sobre a dinâmica celular / molecular de cada maneira de "adoecer" do organismo.

Atualmente, como há um século, o organismo é visto como exposto a um ambiente repleto de germes que 0 ameaçam, e a atividade imunológica é vista como seu principal mecanismo de defesa anti-infecciosa, capaz de reconhecer, de forma específica, uma variedade praticamente ilimitada de agentes de doença. Ao mesmo tempo, isso impediu o estudo de uma "fisiologia imunológica", no sentido de operações imunológicas "normais", como se a atividade imunológica só fosse evocada em condições anormais, quando o organismo é invadido por materiais estranhos.

Mas a penetração de materiais "estranhos" no organismo não é um evento "anormal": as proteínas estranhas que mais freqüentemente penetram o corpo derivam da alimentação normal e da microbiota autóctone, não-patogênica. A dieta humana contém milhares de proteínas diferentes e elas penetram a circulação durante a alimentação, em quantidades que são imunologicamente relevantes ${ }^{39}$. Quanto à microbiota autóctone, apenas na mucosa oral humana, há cerca de 600 espécies bacterianas, mas apenas uma meia dúzia delas se envolve, eventualmente, em atividades patogênicas ${ }^{45}$. Enfim, embora haja claras evidências de que proteínas da dieta e da flora autóctone atuam sobre o sistema imune, esses contatos não geram respostas imunes cada vez mais intensas, como o conceito de "memória" imunológica sugere.

Para acomodar esses efeitos "especiais" de antígenos que não promovem respostas imunes como imaginávamos, os imunologistas criaram uma "imunologia das mucosas" e hoje, membros de uma Society for Mucosal Immunology promovem reuniões separadas, antes dos Congressos Mundiais de Imunologia. Nesse isolamento, há uma inversão irônica: a alimentação e a convivência harmônica com o mundo microbiano passaram a ser vistos como aspectos "especiais" da atividade imunológica, enquanto que o que se passa no "adoecer" é visto como o operar normal do sistema imune. 
No início do século XX, compreendeu-se que a atividade imunológica pode, em si mesma, ser lesiva ao corpo. Clemens von Pirquet criou o termo "alergia" para designar essa forma lesiva de operar do organismo (allos + ergon = outro + operar), a doença como desvio da reatividade fisiológica ${ }^{46}$; essa idéia foi fundamental para a patologia médica da primeira metade do século $X X^{44}$. Meio século depois, surgiu o conceito de doenças "autoimunes" 47 , que não foram entendidas como uma forma de "alergia". Mas ambas essas visões predominantes, de "alergia" e "auto-imunidade", são vistas como imperfeições dos mecanismos de imunidade: um estranhamento exagerado de materiais inócuos (hipersensibilidade), ou desvios no alvo da imunidade, levando ao "estranhamento" do próprio corpo.

Essa maneira de ver não explica a existência de "portadores sãos" de germes e vírus potencialmente patogênicos; nem porque não somos todos alérgicos; nem porque, usualmente, não nos auto-agredimos, já que todos dispomos de abundantes linfócitos auto-reativos ${ }^{11}$. Por outro lado, em uma visão sistêmica, a patogênese pode surgir pelo desentrosamento de uma parcela do sistema imune, que adquira uma autonomia espúria; uma patogênese por incompletude. Vejamos.

\section{A sindrome de Omenn}

Jenner havia proposto a vacinação contra a varíola, na Inglaterra, 80 anos antes; e Pasteur generalizou a idéia de imunização preventiva com germes atenuados. Entretanto, como vimos, a "defesa imunológica" não é um mecanismo, mas sim um resultado possível do entrosamento de muitos mecanismos envolvidos no viver.

A síndrome de Omenn é uma grave anomalia congênita humana, caracterizada como um desarranjo na expressão de linfócitos T, células de Langherans, eosinófilos e uma síntese elevada de IgE. Geralmente, o timo e os linfonodos estão esvaziados de linfócitos. As lesões na pele e na medula óssea lembram a doença do transplante-contrahospedeiro (Graft versus Host Disease, GvHD) congênita, pela invasão do feto por linfócitos maternos, mas um quimerismo (com células maternas) nunca foi demonstrado nesses pacientes. As bases celulares da síndrome de Omenn são distintas ${ }^{48,49}$.

A produção dos receptores clonais dos linfócitos $T$ (TCR) e B (BCR) requer rearranjos de segmentos gênicos. Esses rearranjos são iniciados por duas proteínas expressas exclusivamente em linfócitos, denominadas Rag-1 e Rag-2 (de Recombinase Activating Gene). Mutações que invalidem a função de qualquer dessas duas proteínas anulam o início da recombinação V(D)J, resultando em uma síndrome de imunodeficiência severa, conhecida como SCID (Severe Combined ImmunoDeficiency), na qual linfócitos $T$ ou $B$ adultos não se formam. Na síndrome de Omenn, há mutações em Rag1 ou em Rag-2, que não anulam totalmente a linfopoiese. Como resultado, surgem alguns poucos clones de linfócitos T, que são ativados e formam uma coleção oligoclonal. De uma forma ainda obscura, essa oligoclonalidade é importante na patogênese da síndrome de Omenn ${ }^{48,49}$.

Tais formas de oligoclonalidade, isto é, grupos de linfócitos indevidamente expandidos em relação ao sistema, têm sido experimentalmente caracterizadas em diversos cenários clínicos e experimentais. Um dos mais interessantes está nas doenças auto-imunes, como o lúpus eritematoso sistêmico ${ }^{50}$, a aterosclerose ${ }^{51}$, esclerose sistêmica, entre outras.

\section{Linfopoiese estimulada por linfopenia (ou "homeostática") e a $\lg E$}

$\mathrm{Na}$ arena experimental, há inúmeros exemplos de "patogênese por uma incompletude" do sistema imune. Quando animais imunodeficientes, como mutantes atímicos (sem timo) e em vários tipos de animais knockouts, são transfundidos com uma variedade sub-ótima de linfócitos T singênicos, esses linfócitos se expandem exageradamente e podem criar situações patogênicas fatais ${ }^{52,53}$. Como componente inexplicado dessas expansões, inclui-se uma síntese muito elevada de lgE ${ }^{54}$.

A IgE é o isotipo de imunoglobulinas menos abundante no plasma e sua elevação é tradicionalmente associada a processos alérgicos ${ }^{3}$. Mas uma produção elevada de IgE acompanha também outros estados patológicos, que dificilmente poderiam ser classificados como "alérgicos", tais como: intoxicação por metais pesados ${ }^{55}$, doenças auto-imunes, síndromes de imunodeficiência congênita ${ }^{56}$ e reações transplante-contra-hospedeiro ${ }^{57}$. Também característica da infecção por helmintos, a produção de IgE nem sempre pode ser atribuída a respostas "alérgicas" a antígenos dos parasitas ${ }^{58}$.

Em muitos desses estados patológicos, a síntese aumentada de IgE pode estar associada a uma oligoclonalidade e há um exemplo experimental recente que torna essa associação evidente de forma extrema. Camundongos sem linfócitos (Rag-KO) receberam apenas um clone de linfócitos T e um clone de linfócitos B. Uma única imunização desses animais, com um conjugado das duas proteínas reconhecidas por esses clones, resultou na síntese de lgE em níveis centenas de vezes acima do nível normal $(30-200 \mu \mathrm{g} / \mathrm{ml})$. Essa produção exagerada de IgE era evitada pela infusão de linfócitos T CD4+ de animais normais (policlonais). Isso sugere que, em indivíduos normais, a produção de IgE é contida pela atividade policlonal de células T CD4 $+{ }^{54}$.

Esse mesmo grupo de pesquisadores havia demonstrado que a atividade policlonal de células T CD4+ normais, mas não células T monoclonais (anti-OVA), pode evitar a encefalomielite que emerge "espontaneamente" em camundongos "monoclonais" contendo exclusi- 
vamente células $\mathrm{T}$ reativas com a proteína básica da mielina (MBP) e que essa emergência pode ser inibida por células $\mathrm{T}$ normais ${ }^{59}$.

\section{Uma mudança de paradigmas}

O "paradigma" do "estranhamento", que governa o pensamento tradicional na Imunologia, propõe o reconhecimento específico de antígenos por linfócitos. Como um princípio explicativo, o "estranhamento" tende a ocultar o problema que afirma explicar. A Teoria de Seleção Clonal, como, aliás, seu nome indica, é uma teoria sobre clones linfocitários, e sua ativação. Ela não explica o sistema imune e sua organização. Do ponto de vista tradicional (clonal), a atividade imunológica só pode pecar por excesso, insuficiência ou desvio do desempenho clonal. A Teoria não considera importante a variedade (diversidade, clonalidade) dos linfócitos envolvidos em um dado evento, nem considera que essa pode ser a variável que representa a diferença entre uma operação fisiológica e a patologia, porque, na realidade, na Teoria não se refere à fisiologia do sistema.

O sistema imune se organiza epigeneticamente pelo entrosamento de produtos de conjuntos de genes-V (dos BCR e TCR) e de produtos do $\mathrm{MHC}^{47}$. Cedo, na ontogênese, se estabelece uma organização dinamicamente estável e fechada sobre si mesma que, sob a influência de imunoglobulinas maternas ${ }^{22}$, se completa e daí em diante se mantém inalterada, através do viver saudável, como demonstrado pela presença, no plasma, de padrões robustos de imunoglobulinas naturais ${ }^{26}$.

Esses padrões de atividade se alteram em doenças autoimunes e em formas graves de parasitoses crônicas, tanto em humanos ${ }^{42}$ quanto em modelos animais ${ }^{43}$. Em uma grande variedade de estados patológicos, há evidências de ativação oligoclonal, os linfócitos $T$, similares às observadas no povoamento de organismos imunodeficientes com uma variedade sub-ótima de linfócitos T e na síndrome de Omenn, uma imunodeficiência congênita grave de seres humanos ${ }^{48,49}$. Uma oligoclonalidade T CD4+ freqüentemente se associa a uma síntese elevada de lgE.

Propomos, portanto, uma generalização: que a imunopatologia de doenças infecciosas, alérgicas e autoimunes freqüentemente envolvem uma incompletude que se expressa através da expansão oligoclonal de linfócitos T. Em alguns casos, essa expansão pode derivar da ação de superantígenos, ou seja, de moléculas que atuam preferencialmente sobre certas famílias de linfócitos $\mathrm{T}$, por trajetos não-fisiológicos de ativação. Mais importante, porém, seria caracterizar situações nas quais a expansão resultasse de desvios da própria dinâmica fisiológica do sistema imune. Exemplos importantes nessa direção poderiam ser a tendência à oligoclonalidade que acompanha o envelhecimento, a reatividade a alguns tipos de vírus, como o citomegalovírus (CMV), ou uma combinação desses fatores ${ }^{59}$.

\section{ENTREVER, DE RELANCE, O FUtURO IMEDIATO}

A imunologia atual é parte importante do conhecimento biomédico e, como tal, incorpora suas vantagens e desvantagens. As vantagens derivam do enorme poder de análise e intervenção que possibilita o isolamento e a modificação intencional de genes e proteínas. É possível, por exemplo, gerar em animais anticorpos monoclonais com uma especificidade definida e depois "humanizá-los", ou seja, transformá-los em moléculas que organismos humanos produziriam ${ }^{59}$. Todo esse imenso poder tecnológico esbarra em nossa incapacidade de conceber sistemas complexos e de entender processos não-lineares ${ }^{60}$.

A grande lacuna em nosso conhecimento, porém, é a falta de uma visão do organismo. Em um pequeno curso que orientamos recentemente, profissionais de acupuntura e homeopatia buscavam um paralelo entre a imunologia e suas maneiras particulares de ver. Foram desencantados ao ouvir que isso seria impossível, já que eles partem de uma visão do organismo, seja ela correta ou não, enquanto que a imunologia não dispõe de uma visão desse tipo. $\mathrm{Na}$ visão imunológica, na melhor das hipóteses, o organismo é apenas o meio indefinido onde o sistema imune opera; na pior, é apenas um vaso (um veículo) que contém uma coleção desconjuntada de clones linfocitários. Não só nos falta uma visão do organismo sadio, como nos falta, também, uma maneira geral de abordar sua patologia, o adoecer. A idéia "portador-são" foi omitida da Teoria dos Germes que, ampliada em "Teoria das Causas", se ressente também de conhecimentos elementares para explicar por que, tantas vezes, frente a situações nas quais deveríamos adoecer, permanecemos sadios. $\mathrm{O}$ que nos falta nessas situações é a visão do organismo; faltam os termos com que formularíamos perguntas que queremos ver respondidas. Se não temos ainda sequer meios de perguntar o que queremos saber, busquemos os breves relances que nos permitem antever caminhos pelos quais passaremos.

\section{Imunoglobulina Intravenosa, idiotipos e vacinação de célula T}

Um dos avanços recentes da imunoterapia foi o uso endovenoso de altas doses de imunoglobulinas (Ig) preparadas a partir do soro de milhares de doadores saudáveis, abreviado como IVlg61. Como se seguisse uma tradição indesejada, o uso de IVIg foi desenvolvido empiricamente, e não sabemos de que deriva sua eficácia, às vezes espetacularmente presente, outras vezes apenas paliativa, às vezes ausente. Nossa ignorância reflete a falta de entendimento sobre o organismo, mas é bem provável que as IVlg atuem através das regiões variáveis, pela modificação da conectividade idiotípica. A proposta recente de utilizar uma população de imunoglobulinas isoladas em colunas de anticorpos específicos, ou seja, 
isolar do pool das IVIg as Ig com conexões consideradas relevantes, demonstrou, por exemplo, uma maior eficácia de idiotipos anti-anti-DNA no tratamento de síndromes similares ao lúpus eritematoso em camundongos, inaugurando o que Shoenfeld chama de idiotypic-IVIg (fig. 2) ${ }^{62}$. É possível, portanto, que os efeitos terapêuticos da IVIg se devam, em cada caso, a uma diminuta parcela de idiotipos, capaz de restaurar, no organismo doente, uma conectividade perdida entre seus próprios componentes. Isso explicaria o caráter errático de sua eficácia.

Analogamente, Achiron e colaboradores mostraram a segurança e eficácia da vacinação com células $T$ para 0 tratamento de uma forma de esclerose múltipla humana não-respondedora aos tratamentos disponíveis ${ }^{63}$. A vacinação T consiste na identificação de grupos de linfócitos $\mathrm{T}$, cuja reatividade se encontra expandida (oligoclonais) e na vacinação com estas células inteiras atenuadas ou fragmentos (CDR3) dos TCR das mesmas, sintetizados por biologia molecular. A vacinação gera respostas antiidiotípicas com efeitos terapêuticos (fig. 3) ${ }^{64}$.

\section{Imunoblot semiquantitativo e chip de antígenos}

Em uma fronteira mais básica, destacamos a caracterização de perfis robustos de reatividade linfocitária. Em grande parte, esses resultados ainda se limitam aos linfócitos B, ou seja, à reatividade das IgM ou IgG circulantes, mas já se esboçam diversos métodos de análise da reatividade de linfócitos $T$ com coleções de peptídeos ${ }^{65}$.

Há vários aspectos relevantes nesses achados. 0 primeiro é a clara demonstração de que cedo, na ontogênese de cada organismo e sob a influência de fatores maternos, formam-se redes robustas, com uma conectividade estável, de forma que o organismo exibe um perfil regular e previsível de reatividade com misturas antigênicas complexas, contra as quais não foi "imunizado"21. Por si só, a estabilidade desses perfis de reatividade mostra que o sistema imune não é um conjunto desconectado de linfócitos. Em segundo lugar, há nítidas evidências de que determinados estados patológicos (doenças auto-imunes, parasitoses crônicas), em indivíduos

\section{Imunoglobulina Anti-idiotípica}
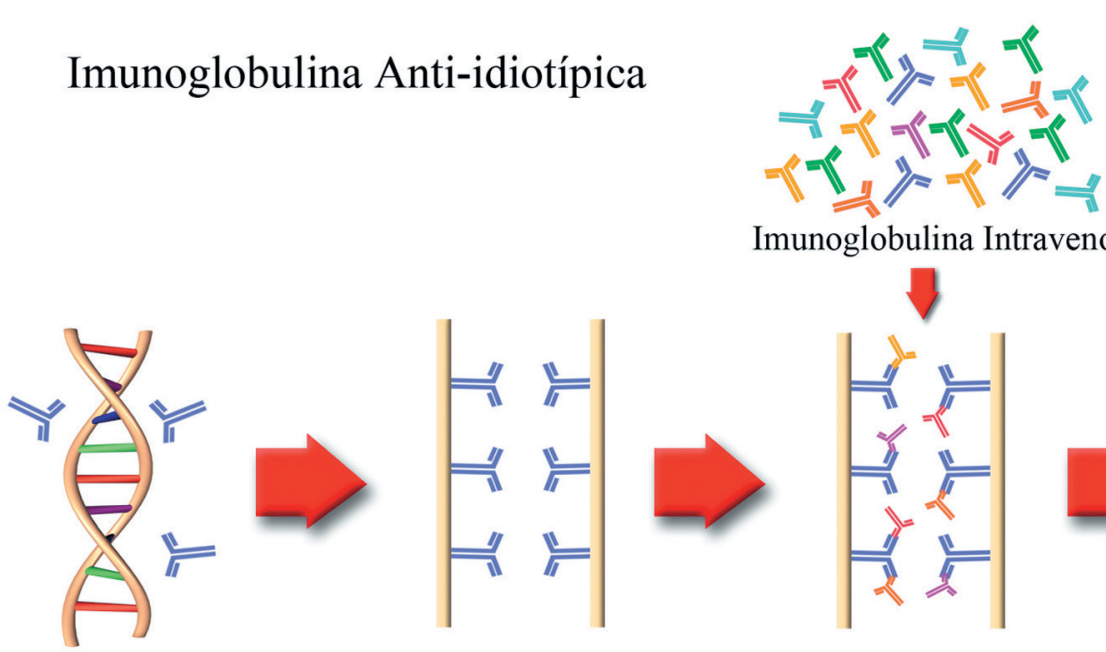

Imunoglobulina Intravenosa

Imunoglobulina Anti-dsDNA

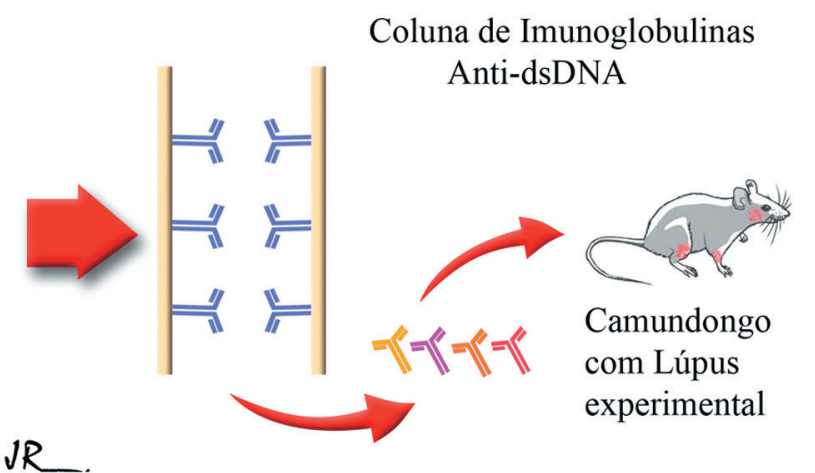

Adsorção de Imunoglobulinas Anti-Idiotipo Anti-dsDNA

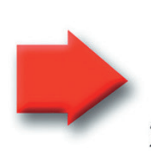

$200 \times$ mais efetivo no tratamento de Lúpus experimental

Fig. 2 - Imunoglobulina intravenosa idiotípica. Na ilustração observamos anticorpos anti-DNA dupla hélice (dsDNA) presentes em pacientes com lúpus eritematoso sistêmico. Em seguida observamos uma coluna construída com estes anticorpos, que recebe Imunog/obulina Intravenosa que contém, entre muitas ouras reatividades, anticorpos que reagem com o idiotipo dos anticorpos anti-dsDNA (anti-anti-dsDNA). No próximo passo, os anticorpos anti-anti-dsDNA são infundidos em um camundongo com lúpus experimental que apresenta clara melhora nos parâmetros da atividade da doença como proteinúria, e depósitos imunes cutâneos 


\section{Vacinação de Célula T}

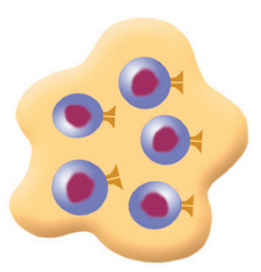

Linfócitos que proliferam em resposta à MOG ou MPB de pacientes com esclerose múltipla "Linfócitos Patogênicos"

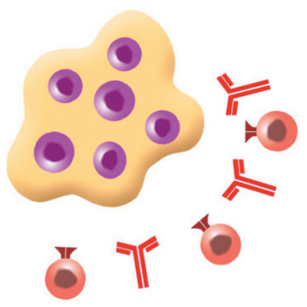

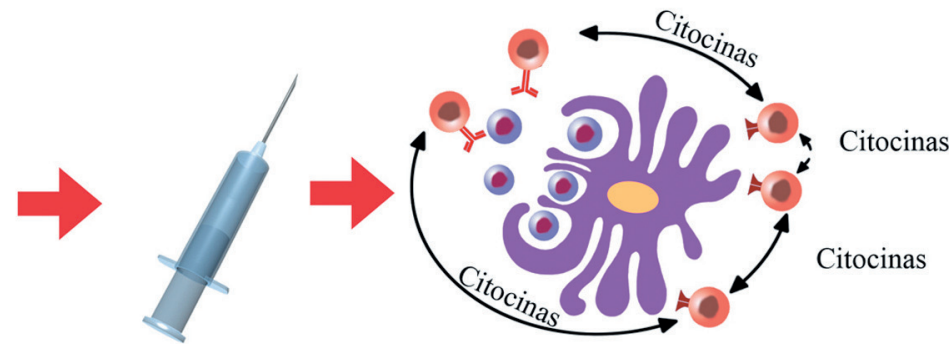

Vacina intra-muscular com os linfócitos inteiros

\author{
Apresentação dos \\ peptídeos dos linfócitos \\ vacinados (oligoclonais) \\ à Linfócitos $\mathrm{T}$ e interação \\ com células $B$
}

I Linfócitos T e Imunoglobulinas Anti-idiotípicos entre outras reatividades

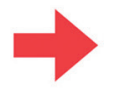

Reconexão das expansões oligoclonais ao sistema linfocitário

Fig. 3 - Vacinação de célula T. Em 1 observamos um grupo de linfócitos que foram isolados por provas de linfoproliferação à Myelin Oligodendocyte Protein (MOG) e Myelin Basic Protein (MBP) e são representativos de expansões oligoclonais em pacientes com esclerose múltipla (EM). Estes linfócitos são separados, irradiados e infundidos em pacientes com EM. A vacinação com as células $T$ faz com que o sistema imune do indivíduo reaja em diferentes eixos à esta população oligoclonal, reincorporando-a à regulação sistêmica

diferentes, seguem padrões similares de modificações. Isso sugere algo importantíssimo: que os estados patológicos seguem uma dinâmica estrutural definida, que se reflete em mudanças não aleatórias nos padrões de reatividade linfocitária. Haveria, portanto, uma identidade característica em diversos estados patológicos. 0 immunoblot semiquantitativo desenvolvido por Nóbrega e colaboradores ${ }^{36}$ e os chips de antígeno criados por Cohen e cols. ${ }^{66}$ são ferramentas úteis no estudo destes padrões de reatividade linfocitária, talvez reflexo dos Eigen-states ("auto-estados") do sistema imune, como antevisto por Jerne em sua Teoria da Rede Idiotípica, há trinta anos ${ }^{67}$.

\section{Tudo já foi dito}

Esses desenvolvimentos são coerentes com o conceito original de "alergia" sugerido por Clemens von Pirquet ${ }^{46}$, como um operar alternativo no qual os mecanismos fisiológicos se tornam patogênicos. Segundo Parnes, esse conceito esteve nos bastidores do desenvolvimento da patologia médica durante toda a primeira metade do século XX. Esse conceito diminui a importância dada à discriminação self / nonself, e às doenças auto-imunes, conceitos introduzidos por Burnet, em sua Teoria da Seleção Clonal $^{44}$. O reconhecimento atual de que há uma abundante reatividade do sistema imune de organismos sadios com o próprio corpo invalida a noção de "autoreatividade" como patogênica; o sistema imune não pode mais ser destacado do organismo do qual é um componente. Um entendimento das "doenças auto-imunes" só virá com uma compreensão melhor do organismo e de sua fisiologia.

Em um seminário no Instituto Wellcome para história da medicina em Londres, Robin Coombs, criador do teste homônimo para investigação de anemia hemolítica, sugeriu que o termo "auto-alergia" seria mais coerente que a idéia de "auto-imunidade" 68 que, entretanto, já foi consagrado pelo uso.

\section{Doenças cardiovasculares}

O impacto mais imediato de uma imunologia "centrada no organismo" é uma aproximação com doenças antes não associadas ao sistema imune. As doenças cardiovasculares, principal causa de morte no Brasil e no mundo, entram de forma significativa nessa história. 
Mecanismos imunológicos estão claramente envolvidos na aterosclerose que é o principal processo gerador das doenças cardíacas. Isso abre possibilidades promissoras de diagnóstico, prognóstico e terapêuticas ${ }^{69}$. 0 estudo dos perfis de reatividade linfocitária citados acima é uma ferramenta promissora para o que os cardiologistas chamam de estratificação de risco cardiovascular, ou seja, identificar em que estágio se encontra a doença aterosclerótica e, talvez, sugerir intervenções, como a IVIg idiotípica, para evitar o desfecho mais temido: o infarto agudo do miocárdio. Iniciamos o estudo dos padrões de reatividade linfocitária com o Imunoblot semiquantitativo em doenças cardiovasculares e observamos claras modificações sugestivas de oligoclonalidade em situações como as miocardites e miocardiopatia dilatada idiopática ${ }^{70}$. Deste modo, abrimos possibilidades para um diagnóstico que hoje depende de biópsia endomiocárdica e seus altos riscos, e amplia a própria compreensão fisiopatológica da doença.

Experimentos mais recentes de nosso grupo sugerem que, mesmo processos agudos, tidos como não imunológicos, como o infarto do miocárdio, são capazes de modificar os padrões de reatividade linfocitária em camundongos (no prelo). Outros grupos descreveram elevação de títulos de auto-anticorpos no infarto agudo do miocárdio, como a anti-miosina cardíaca ${ }^{71}$, anti-beta 2 Glicoproteína $\mathrm{I}^{72}$; esses dados têm, inclusive, implicações prognósticas e sugerem o interesse de intervir imunologicamente nesse processo.

Certamente, é assustadora a antevisão de uma tarefa monumental como a de reformular a maneira de ver toda a imunologia. Mas essa emoção é preferível à protelação indefinida da necessidade de encará-la. Só nos resta confiar em que seremos bem sucedidos no redirecionamento de nosso arsenal tecnológico.

\section{REFERÊNCIAS}

1. Delves PJ, Roitt IM. The immune system. Second of two parts. N EngI J Med 2000; 343(2): 108-17.

2. Delves PJ, Roitt IM. The immune system. First of two parts. N Engl J Med 2000; 343(1): 37-49.

3. Kay AB. Allergy and allergic diseases. Second of two parts. N Engl J Med 2001.344(2): 109-13.

4. Kay AB. Allergy and allergic diseases. First of two parts. N Engl J Med 2001; 344(1): 30-7.

5. Davidson A, Diamond B. Autoimmune diseases. N Engl J Med 2001; 345(5): 340-50.

6. Kamradt T, Mitchison NA. Tolerance and autoimmunity. N Engl J Med 2001; 344(9): 655-64.

7. Rinkevich B. Invertebrates versus vertebrates innate immunity: In the light of evolution. Scand J Immunol 1999; 50(5): 456-60.

8. Rinkevich B. Primitive immune systems: are your ways my ways? Immunol Rev 2004; 198: 25-35.

9. Cohen IR, Hershberg U, Solomon S. Antigen-receptor degeneracy and immunological paradigms. Mol Immunol 2004; 40(14-15): 993-6.

10. Ignatowicz L, Kappler J, Marrack P. The repertoire of T cells shaped by a single MhC/peptide ligand. Cell 1996; 84: 521-9.

11. Coutinho AM, Kazatchkine D, Avrameas S. Natural autoantibodies. Curr Opin Immunol 1995; 7: 812-18.

12. Faria AM, Weiner HL. Oral tolerance: mechanisms and therapeutic applications. Adv Immunol 1999; 73: 153-264.

13. Vaz NM, Faria AMC, Verdolin BA, Carvalho CR. Immaturity, ageing and oral tolerance. Scand J Immunol 1997; 46: 225-9.

14. Vaz NM, Faria AMC, Verdolin BA, Silva Neto AF, Menezes JS, Carvalho CR. The conservative physiology of the immune system. Braz J Med Biol Res 2003; 36; 13-22.

15. Curtis MA. Summary: Microbiological perspective. Mol Immunol 2003; 40: 477-9.

16. Legge KL, Gregg RK, Maldonado-Lopez R, Li L, Caprio JC, Moser M et al. On the role of dendritic cells in peripheral $T$ cell tolerance and modulation of autoimmunity. J Exp Med 2002; 196(2): 217-27.

17. Cohen IR. The cognitive paradigm and the immunological homunculus. Immunol Today 1992; 13(12): 490-4.

18. Maturana HR, Varela F. Autopoiesis and Cognition: the Realization of the Living. Amsterdam: Reidel, 1980.

19. Maturana HR, Varela FJ. The Tree of Knowledge. Biological Basis of Human Understanding. Boston: New Science Library, 1987.

20. Maturana HR. The mind is not in the head. J Social Biol Struct 1985; 8: 308-311.

21. Mouthon L, Lacroix-Desmazes S, Nobrega A, Barreau C, Coutinho A, Kazatchkine MD. The self-reactive antibody repertoire of normal human serum IgM is acquired in early childhood and remains conserved throughout life. Scand J Immunol 1996; 44(3): 243-51.

22. Lemke H, Coutinho A, Lange H. Lamarckian inheritance by somatically acquired maternal IgG phenotypes. Trends Immunol 2004; 25(4): 180-6.

23. Haury M, Sundblad A, Grandien A, Barreau C, Coutinho A, Nobrega A. The repertoire of serum IgM in normal mice is largely independent of external antigenic contact. Eur J Immunol 1997; 27(6): 1557-63.

24. Freitas A, Chen J. Forum in Immunology. Introduction: regulation of lymphocyte homeostasis. Microbes and Infection 2002; 4: 529-30.

25. Nóbrega AB, Stransky N, Nicolas, Coutinho A. Regeneration of natural antibody repertoire after massive ablation of lymphoid system: robust selection mechanisms preserve antigen binding specificities. J Immunol 2002; 169 (6): 2971-8.

26. Mouthon L,Nobrega A, Nicolas N, Kaveri SV, Barreau C, Coutinho A, Kazatchkine MD. Invariance and restriction toward a limited set of self-antigenscharacterize neonatal IgM antibody repertoires and prevail in autoreactive repertoires of healthy adults. Proc Natl Acad Sci USA 1995; 92(9): 3839-43.

27. Maturana $\mathrm{H}$, Mpodozis J, Letelier JC. Brain, language and the origin of human mental functions. Biol Res 1995; 28: 15-26.

28. Vaz NM. The cellular and molecular correlates of immunological phenomena. Contrasting two explanatory pathways. Braz J Med Biol Res 1996; 26: 545-53.

29. Vaz NM. Immunology: elementary concepts and misconceptions. In: BiomatIII (Anais do III Simpósio Brasileiro de Biologia Matemática e Computacional), Ed. Rio de Janeiro: Rubem Mondaini. November 22-26/2003: FioCruz/Cope-UFRJ, 2004.

30. Hozumi N, Tonegawa S. Evidence for somatic rearrangement of immunoglobulin genes coding for variable and constant regions. Proc Natl Acad Sci U S A 1976; 73(10): 3628-32. 
31. Tonegawa S. Somatic generation of immune diversity. Nobel lecture in physiology or medicine 1987. In Vitro Cell Dev Biol 1988; 24(4): 253-65.

32. Benacerraf B, Daussett J, Snell GD. The Nobel Lectures in Immunology. The Nobel Prize for Physiology or Medicine, 1980 awarded to Baruj Benacerraf, Jean Daussett \& George D. Snell. Scand J Immunol 1992; 35: 373-98.

33. Benacerraf B. Antigen processing and presentation. The biologic role of $\mathrm{MHC}$ molecules in determinant selection. J Immunol 1988; 141(Suppl 7): S17-20.

34. Lanzavecchia A. Antigen specific interaction between $T$ and $B$ cells. Nature 1985; 314: 537-9.

35. Ada G. Twenty years into the saga of MHC-restriction. Immunol Cell Biol 1994; 72: 447-54.

36. Nóbrega A, Haury M, Grandien A, Malanchere E, Sundblad A, Coutinho A. Global analysis of antibody repertoires. II. Evidence for specificity, self-selection and the immunological "homunculus" of antibodies in normal serum. Eur J Immunol 1993; 23(11): 2851-9.

37. Vasconcellos R, Nobrega A, Haury M, Viale AC, Coutinho A. Genetic control of natural antibody repertoires: I. IgH, MHC and TCR beta loci. Eur J Immunol 1998; 28(3): 1104-15.

38. Silva Neto AF, Vaz, NM. Natural IgG and IgM antibodies reactivity in the horse. In: XXV Meeting Braz. Soc. Immunology, 2000, Florianópolis, SC. Proc XXV Meeting Braz. Soc. Immunology (II07), 2000. p. 296.

39. Menezes JS, Mucida DS, Cara DC et al. Stimulation by food proteins plays critical role in the maturation of the immune system. Int Immunol 2003; 15: 447-55.

40. Hooijkaas H, Bos N, Benner R, Pleasants JR, Wostmann BS. Isotype distribution and specificity repertoire of 'spontaneously' occurring ('background') immunoglobulin-secreting cells in germfree mice fed chemically defined ultrafiltered 'antigen-free' diet. Prog Clin Biol Res 1985; 181: 355-8.

41. Verdolin BA, Ficker SM, Faria AMC, Vaz NM, Carvalho CR. Stabilization of serum antibody responses triggered by initial mucosal contact with the antigen independently of oral tolerance induction. Braz. J Biol Med Res 2001; 34: 211-19.

42 Fesel C, Goulart LF, Silva Neto A et al. Increased polyclonal immunoglobulin reactivity toward human and bacterial proteins is associated with clinical protection in human Plasmodium infection. Malaria Journal 2005; 4: 5-13.

43. Vaz NM, Fesel CA, Nobrega AF, Silva Neto AF, Secor WE, Colley DG. Severity of schistosomiasis mansoni in male CBA mice is related to IgG profiles reacting with mouse liver extracts in Panama-blots. In Proc XVI Reunião Annual da Federação de Sociedades de Biologia Experimental (FESBE). Caxambu MG, 2001: 136 (124.003).

44. Parnes O. Trouble from within: allergy, autoimmunity, and pathology in the first half of the twentieth century. Studies in History and Philosophy of Science Part C: Biological and Biomedical Sciences 2003; 34(3): 425-454(30).

45. Curtis MA. Summary: microbiological perspective. Mol Immunol 2003; 40(7): 477-9.

46. Pirquet CV, Schick B. Ueberempfindlichkeit und beschleunigte Reaktion. Muenchener medizinische Wochenschrift, 1906; 53: 66-89.

47. Burnet MCF. Concepts of autoimmune disease and their implications for therapy. Persp Biol Med 1967; 141: 141-51.

48. Villa A, Santagata S, Bozzi F, Giliani S, Frattini A, Imberti L et al. Partial $V(D) J$ recombination activity leads to Omenn syndrome. Cell 1998; 93(5): 885-96.

49. Villa A, Sobacchi C, Notarangelo LD, Bozzi F, Abinun M, Abrahamsen $T G$ et al. V(D)J recombination defects in lymphocytes due to RAG mutations: severe immunodeficiency with a spectrum of clinical presentations. Blood 2001; 97(1): 81-8.
50. Ferreira C, Mouthon L, Nobrega A, Haury M, Kazatchkine MD, Ferreira $E$ et al. Instability of natural antibody repertoires in systemic lupus erythematosus patients, revealed by multiparametric analysis of serum antibody reactivities. Scand J Immunol 1997; 45(3): 331-41.

51. Caligiuri G, Stahl D, Kaveri S, Irinopoulos T, Savoie F, Mandet C et al. Autoreactive antibody repertoire is perturbed in atherosclerotic patients. Lab Invest 2003; 83(7): 939-47.

52. Hirokawa M, Matsutani T, Horiuchi T et al. Miura Extensive clonal expansion of $\mathrm{T}$ lymphocytes causes contracted diversity of complementarity-determining region 3 and skewed T cell receptor repertoires after allogeneic hematopoietic cell transplantation. Bone Marrow Transplant 2001: 27: 607-614.

53. Surh CD, Sprent J. Homeostatic T cell proliferation: how far can $T$ cells be activated to self-ligands? J Exp Med, 2000. 192: F9-F14.

54. de Lafaille MA, Muriglan SM, Sunshine JY et al. Hyper IgE response in mice with monoclonal populations of $B$ and $T$ lymphocytes. J Exp Med 2001; 194: 1349-59.

55. Sapin CF, Hirsch JP, Delaporte H, Bazin, Druet P. Polyclonal IgE increase after $\mathrm{HgCl} 2$ injections in $\mathrm{BN}$ and LEW rats: a genetic analysis. Immunogenetics 1984; 20: 227-36.

56. Erlewyn-Lajeunesse M D. Hyperimmunoglobulin-E syndrome with recurrent infection: a review of current opinion and treatment. Pediatr Allergy Immunol 2000; 11: 133.

57. Claman HN, Spiegelberg HL. Immunoglobulin dysregulation in murine graft-vs-host disease: a hyper-IgE syndrome. Clin Immunol Immunopathol 1990; 56: 46-53.

58. Faulkner H, Turner J, Kamgno J, Pion SD, Boussinesq M, Bradley JE. Age- and infection intensity-dependent cytokine and antibody production in human trichuriasis: the importance of IgE. J Infect Dis 2002; 185: 665-72.

59. Kipriyanov SM, Le Gall F. Generation and production of engineered antibodies. Mol Biotechnol 2004; 26(1): 39-60.

60. Ottino JM. Engineering complex systems. Nature 2004; 427(6973): 399

61. Kazatchkine MD, Kaveri SV. Immunomodulation of autoimmune and inflammatory diseases with intravenous immune globulin. N Engl J Med 2001; 345: 747-55.

62. Shoenfeld Y, Rauova L, Gilburd B, Kvapil F, Goldberg I, Kopolovic $J$ et al . Efficacy of IVIG affinity-purified anti-double-stranded DNA anti-idiotypic antibodies in the treatment of an experimental murine model of systemic lupus erythematosus. Int Immunol 2002; 14(11): 1303-11.

63. Achiron A, Lavie G, Kishner I, Stern Y, Sarova-Pinhas I, Ben-Aharon $T$ et al. $T$ cell vaccination in multiple sclerosis relapsing-remitting nonresponders patients. Clin Immunol 2004; 113(2): 155-60.

64. Matsumoto Y, Jee Y, Sugisaki M. Successful TCR-based immunotherapy for autoimmune myocarditis with DNA vaccines after rapid identification of pathogenic TCR. J Immunol 2000; 164(4): 2248-54.

65. Caligiuri G, Paulsson G, Nicoletti A, Maseri A, Hansson GK. Evidence for antigen-driven T-cell response in unstable angina. Circulation 2000; 102(10): 1114-9.

66. Quintana FJ, Hagedorn PH, Elizur G, Merbl Y, Domany E, Cohen IR. Functional immunomics: microarray analysis of IgG autoantibody repertoires predicts the future response of mice to induced diabetes. Proc Natl Acad Sci USA. 2004; 101 (Suppl 2): 14615-21.

67. Jerne NK. Towards a network theory of the immune system. Ann Immunol (Paris), 1974; 125C(1-2): 373-89.

68. Tansey EM, Catteral PP, Christie DA, Willhoft SV, Reynolds LA.Wellcome Witnesses to Twentieth Centure Medicine. Volume 1: Self and Non-Self: A History of Autoimmunity. Available online : http:/ /www.ucl.ac.uk/histmed/publications/wellcome-witnesses/ witness01.html 1995. 
69. Pordeus V, Shoenfeld Y. Atherosclerosis and autoimmunity: promises for a better cardiovascular future, in SBI na rede 2004;31. Brazilian Society of Immunology. 2004, Available online:http:// www.sbi.org.br/sbinarede/SBInarede31/index.html.

70. Pordeus V, Tostes A, Silva-Neto AF, Dohmann HF, Vaz NM, Mesquita ET. Multiparametric Analysis of Reactivity Profiles of serum IgG of Patients with Myocarditis and Dilated Cardiomyopathy. In: Brazilian Congress on
Heart Failure. São Paulo: Brazilian Society of Cardiology, 2003.

71. Pang H, Liao Y, Wang Z, Dong J, Ju Q. Effect of anti-cardiac myosin antibody on prognosis of patients with acute myocardial infarction. J Tongji Med Univ 2000; 20(1): 46-8.

72. Barshack I, Keren P, Goldberg I, Kopolovic J, Keren G, George J. Relation of preexisting anti-beta2GPI antibodies to infarct size in a rat model. Cardiovasc Pathol 2003; 12(4): 195-201. 